\title{
Biography—Anna Sebestyén, Ph.D.
}

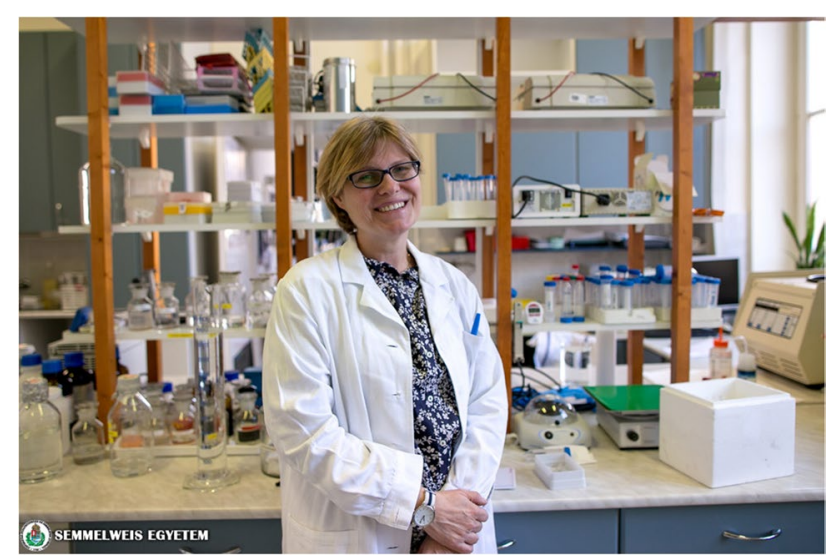

Anna Sebestyén, Ph.D., is a senior research fellow andthe leader of Tumor Biology and the Tumor Metabolism Research Group, as well director of the institutional Tissue and Cell Culture Laboratory of the 1st Department of Pathology and Experimental Cancer Research at Semmelweis University Faculty of Medicine in Budapest, Hungary.

Dr. Sebestyén received her doctoral degree in PathologyOncology. As a biologist, she joined Professor Laszlo Kopper's research group at Semmelweis University investigating apoptosis in lymphoma and altered signaling mechanisms in cancer. She and her research team made significant contributions to the pathological characterization of signaling failures and deregulated mTOR in malignancies. In addition to mapping these alterations in human tumor tissues, they performed metabolic studies involving 2D and 3D cell cultures and 3D bioprinted tissue-like structures. Her ongoing projects focus on the differences between mTORC1 and $\mathrm{C} 2$ complex activity and metabolic heterogeneity/plasticity at the tumor tissue level in various malignancies as well as development of 3D bioprinted models targeting altered metabolic adaptation mechanisms in vitro. She has several clinical collaborations related to pediatric and rare malignancies examining additional treatment options for personalized therapy.

She serves on the editorial board of Pathology and Oncology Research as assistant chief editor and Frontiers in Oncology as associate editor of the Cancer Metabolism Section. Dr. Sebestyén organizes doctoral courses and lectures at Semmelweis University on topics related to immunology, pathology, and genetics. Her mentored graduate and doctoral students received numerous awards and hold several international research and clinical positions. Dr. Sebestyén is the recipient of several teaching and scientific research awards from the prestigious Hungarian Academy of Sciences and Semmelweis and Eötvös Loránd Universities.

Publisher's note Springer Nature remains neutral with regard to jurisdictional claims in published maps and institutional affiliations. 